\title{
Towards the Prediction of Micro-EDM Drilling Performance on WC Varying the Hole Depth
}

\author{
Gianluca D’Urso, Mariangela Quarto, Giuseppe Pellegrini, Chiara Ravasio \\ University of Bergamo - DIGIP, Viale Marconi 5, 24044 Dalmine (BG) - Italy. Email: gianluca.d-urso@unibg.it, mari- \\ angela.quarto@unibg.it, giuseppe.pellegrini@unibg.it, chiara.ravasio@unibg.it
}

\begin{abstract}
The present work deals with the execution of through micro-holes on tungsten carbide plates using a micro-EDM (Electrical Discharge Machining) machine. The investigation focuses on the monitoring of the performance during the drilling phase in order to obtain the in progress behavior of the performance indexes. The experiments were carried out by varying some process parameters such as peak current, voltage and frequency to achieve both high and low power discharge conditions. Regarding electrodes, the most commonly industrial used ones were selected: tubular tungsten carbide and brass. The performance indexes taken into account were machining time, Material Removal Rate (MRR), Tool Wear (TW) and Tool Wear Ratio (TWR). Brass electrode always resulted to be the best solution in terms of drilling speed even though the wear of this electrode type is remarkable higher than the tungsten one. The evolution of the performance indexes during the drilling operation showed the same trend for both electrodes: increasing the hole depth, the drilling operation proceeds in a more difficult way, due to the evacuation of debris that becomes more difficult and therefore the performance indexes get worse. Finally, the technology windows of the cumulated MRR and TWR were defined for both electrode materials, in order to predict the micro EDM process performance varying the hole depth.
\end{abstract}

Keywords: Micro-EDM, Tungsten carbide, Micro-drilling, Process performance, Prediction ability

\section{Introduction}

The current trends in manufacturing technology often deal with the miniaturization of products and components and, consequently, the need for products containing micro-features has shown a noticeable and continuous growth in many fields of application. At the same time, sustainable manufacturing is the most recent trend in today's industrial environment. The selection of the manufacturing processes must take into account both technological aspects and the impact on the environment and resources according to green development strategy. In general, the characteristics of sustainable machining take into account five aspects such as the cost effective, the energy efficient, the use of non lethal substances, waste free and eco friendly [1]. Micro Electrical Discharge Machining $(\mathrm{EDM})$ is a process that operates by a series of rapid electrical discharges in a gap filled with dielectric fluid between a tool and a workpiece material. The electrical energy of the spark is converted into thermal energy causing melting and vaporization of the workpiece surface. Materials removed as debris particles are flushed away by the dielectric flow. Material is removed not only from the workpiece but also from the tool (electrode wear). This technology can be applied on every conductive materials regardless of the mechanical properties and since it is a contact-less process, it is suitable for the fabrication of micro-parts and micro-scale features without distortion or brakeage due to physical forces [2,3].

Form the point of view of the sustainability, EDM process offers some environmental, economic and social concerns like poor material removal rate, electrode wear, high specific energy consumption, deteriorated surface characteristics, hazardous emissions near operator breathing zone, the possibility of fire explosion and toxic waste and sludge generation [4]. EDM is considered one of the most important technologies in micro-drilling, because it is effective in achieving very small and very high aspect ratio burr-free micro-holes. The need for products containing micro-holes has shown a remarkable growth $[5,6]$ since they are widely used for the production of several industrial components such as medical and optical devices, turbine blades cooling channels, diesel fuel injection nozzles. Moreover, EDM is able to machine difficult to cut materials, for example WC-Co composites, and in general where dimensional accuracy with complex geometries are primary requirements [7]. Regarding WC, it has high performing properties in terms of hardness, toughness, low heat sensitivity, high fatigue and corrosion resistance with respect to other more common materials, even though it is more difficult to be machined using conventional technologies. Nowadays, WC and its composites ( $\mathrm{WC}-\mathrm{Co}$ ) are of great interest in the production of cutting tools, dies and other special tools and components [8].

Many process parameters have to be selected for the execution of micro holes using EDM technology such as peak current, voltage, pulse on time, duty cycle, etc. Other parameters are related to the system for example the type of dielectric fluid, tool properties, chemical and physical material properties.

These parameters have a significative effect on both erosion process (material removal rate - MRR, Tool wear ratio - TWR) and machined workpiece properties (dimensional and geometrical accuracy such as diametral overcut - DOC, Taper rate - TR and surface finishing) [9-11].

From the point of view of the sustainability, it can be assumed that the process is more sustainable as the used resources are limited in terms of machining time and electrode wear. Obviously, the sustainability is related to some other aspects such as the dielectric consumption, environmental pollution, smoke, etc. [12]. The selection of the optimal process parameters to maximize MRR 
(Material Removal Rate) and minimize TWR (Tool Wear Ratio) assists the efforts to improve the sustainability of the process. Literature reports several papers about this topic. In $[13,14]$, the optimization of the process parameters in the micro-EDM drilling process of titanium super alloy was conducted. Peak current and pulse on time have a strong influence on machining performances. In particular, material removal rate and tool wear ratio showed a monotonic increase for increasing values of peak current and a relative maximum condition for intermediate values of pulse on time. The overcut of the machined micro-holes also increases for increasing values of peak current and pulse on time.

The effect of peak current, pulse on time, duty factor and electrode speed for the execution of small deep hole in Inconel 718 using EDM technology with a pure electrolytic copper electrode was investigated in [15]. The results revealed that MRR increases with the increase in peak current, duty factor and electrode rotation, whereas depth average surface roughness increases with the increase in peak current and pulse on time. Using a desirability function approach, the parameters were optimized for the maximum MRR with a specified surface roughness.

The influence on the machining characteristics of the operating parameters used for the electro-discharge machining of tungsten carbide was studied in [16]. The effectiveness of the EDM process (peak current, voltage, pulse duration, pulse interval and flushing pressure) was evaluated in terms of material removal rate, relative wear ratio and surface finishing, showing that high material removal rate, low relative wear ratio and good surface finishing are conflicting goals, which cannot be achieved simultaneously with a particular combination of control settings.

From the point of view of both geometry and material electrode, in [17] it was verified their influence on MRR, electrode wear and surface finishing. In [18] it was demonstrated that the single-channel electrode provides better material removal rates and lower electrode wear ratios than multi-channel tubular electrode. However, multichannel electrodes produce better surfaces and lower hardness values than single-channel electrodes. An investigation on the electrode wear behavior of tube and bar electrodes was carried out in [19]; the electrode wear variation under different operating conditions and a method for calculating volumetric wear ratio is proposed.
Process performances risulted affected by tool material when titanium alloy is the workpiece [20]: brass and copper electrodes permit to obtain the minimum machining time while machining time increases a lot using special carbide electrodes. On the contrary, minimization of tool wear ratio can be obtained using special carbide electrodes with respect to copper and brass.

Even if important efforts were made in modelling the EDM and micro-EDM processes, the validation of the models forecasting capabilities by means of experimental tests can be considered still restricted. In some cases, the models have not been experimentally validated while in other cases the campaign was carried out only for restricted clusters of workpiece materials and tools. Moreover, few data are present in literature regarding the variation of process performance during the drilling operation, showing a lack of information about the effect of process duration (e.g. hole depth, machining time) on the general performance indicators.

In the present paper, the investigation focuses on the process performance during the micro-EDM drilling on tungsten carbide plates in order to obtain the "in progress" behavior of the performance indexes. Machining setting, including peak current, open circuit voltage and discharges frequency, were varied to produce low and high discharge power. This study was conducted using different electrode materials (tungsten carbide and brass). The selection of the optimal process parameters contributes to improve the level of the sustainability of the process. Moreover, the effect of the hole depth on the process performance can be evaluated.

\section{Experimental set up}

Experimental tests based on the execution of through micro-holes were carried out using a micro-EDM machine Sarix SX-200. Tungsten carbide plates having a thickness equal to $3 \mathrm{~mm}$ were used as workpiece material. Three process parameters were varied during the experimentation, such as the peak current (I), the voltage (V) and the frequency (F). Two types of tubular electrodes, made of tungsten carbide and brass, having an outer diameter equal to $0.3 \mathrm{~mm}$ and an inner diameter equal to 0.12 $\mathrm{mm}$, were used. Hydrocarbon oil was used as dielectric fluid and an internal electrode washing pressure equal to 30 bar was set for all the experiments. Table 1 shows the fixed process parameters.

Tab. 1 Fixed process parameters

\begin{tabular}{|l|c|c|c|c|c|c|}
\hline Electrode & Polarity & Ton $[\mu \mathrm{s}]$ & Gain & Gap [\%] & Energy & Regulation \\
\hline $\begin{array}{l}\text { Tungsten Car- } \\
\text { bide }\end{array}$ & $-(\mathrm{neg})$ & 5 & 40 & 20 & 365 & $03-01$ \\
\hline Brass & $-(\mathrm{neg})$ & 3.8 & 120 & 5 & 365 & $03-01$ \\
\hline
\end{tabular}

A Central Composite Design (CCD) with three levels, central point and five repetitions were used to define the combination of the process parameters and the experimental sequence for each tool material type. The combination of the variable parameters resulted into 15 combinations of process parameters and in a total amount of 100 micro-holes (Table 2). The set values (peak current, voltage and frequency) defines the technology (from TC.1 to TC.15 for tungsten carbide electrode, from B.1 to B.15 for brass one). The fixed parameters and the ranges of the variable ones differ for the two electrode materials; this solution was used in order to test suitable technology win- 
dows (in other words, ranges of suitable process parameters) for both the materials. The execution order of the experiments was randomized to avoid possible systematical errors.

The in-progress drilling process was studied carrying out each hole in 10 sub-steps having an equal tool displacement. In some cases the through holes were obtained with a tool displacement lower than the maximum stroke, due to the large difference of tested process parameters.
The machining time of each sub-step was also recorded. At the end of each drilling sub step, the tool wear was measured by an electrode touching operation in a specific reference point as the difference between the initial and the final length of the electrode. In order to ensure the same initial conditions of the electrode for each hole, the electrode tip was cut using the wire EDM unit at the end of each hole drilling.

Tab. 2 Combination of process parameters based on CCD

\begin{tabular}{|c|c|c|c|c|c|c|c|}
\hline \multirow{2}{*}{ Tool type } & \multicolumn{3}{|c|}{ Tungsten Carbide } & & \multicolumn{3}{|c|}{ Brass } \\
\hline & I [index] & $\mathrm{V}[\mathrm{V}]$ & $\mathrm{F}[\mathrm{kHz}]$ & & I [index] & $\mathrm{V}[\mathrm{V}]$ & $\mathrm{F}[\mathrm{kHz}]$ \\
\hline TC.1 & 40 & 110 & 83 & B.1 & 26 & 120 & 130 \\
\hline TC.2 & 30 & 100 & 90 & B.2 & 40 & 100 & 110 \\
\hline TC.3 & 50 & 100 & 90 & B.3 & 40 & 140 & 110 \\
\hline TC.4 & 30 & 120 & 90 & B.4 & 40 & 100 & 150 \\
\hline TC.5 & 50 & 120 & 90 & B.5 & 40 & 140 & 150 \\
\hline TC.6 & 40 & 93 & 100 & B.6 & 60 & 120 & 96 \\
\hline TC.7 & 23 & 110 & 100 & B.7 & 60 & 86 & 130 \\
\hline TC.8 & 40 & 110 & 100 & B.8 & 60 & 120 & 130 \\
\hline TC.9 & 57 & 110 & 100 & B.9 & 60 & 154 & 130 \\
\hline TC.10 & 40 & 127 & 100 & B.10 & 60 & 120 & 160 \\
\hline TC.11 & 30 & 100 & 110 & B.11 & 80 & 100 & 110 \\
\hline TC.12 & 50 & 100 & 110 & B.12 & 80 & 140 & 110 \\
\hline TC.13 & 30 & 120 & 110 & B.13 & 80 & 100 & 150 \\
\hline TC.14 & 50 & 120 & 110 & B.14 & 80 & 140 & 150 \\
\hline TC.15 & 40 & 110 & 117 & B.15 & 94 & 120 & 130 \\
\hline
\end{tabular}

\section{Evaluation of process performance}

The selected performance criteria for the micro-holes drilling are reported in Table 3 where:

$\mathrm{t}=$ machining time $[\mathrm{s}]$

$\mathrm{TW}=$ tool wear $[\mathrm{mm}]$

$\mathrm{MRR}=$ material removal rate $\left[\mathrm{mm}^{3} / \mathrm{s}\right]$
Dtop= top diameter of the hole [mm]

Dbottom=bottom diameter of the hole [mm]

MRworkpiece $=$ material removed from the workpiece $\left[\mathrm{mm}^{3}\right]$

$\mathrm{h}=$ thickness of the plate [mm]

MRtool $=$ material removed from the tool $\left[\mathrm{mm}^{3}\right]$

Tab. 3 Performance criteria for the evaluation of the micro EDM drilling process

\begin{tabular}{|l|l|}
\hline Criteria & Formula \\
\hline $\mathrm{t}[\mathrm{s}]$ & - \\
\hline $\mathrm{TW}[\mathrm{mm}]$ & - \\
\hline $\operatorname{MRR}\left[\mathrm{mm}^{3} / \mathrm{s}\right]$ & $M R R=\frac{M R_{\text {workpiece }}}{t}=\frac{\pi h\left(D_{\text {top }}^{2}+D_{\text {top }} D_{\text {bottom }}+D_{\text {bottom }}^{2}\right)}{12 t}$ \\
\hline TWR [-] & $T W R=\frac{M R_{\text {tool }}}{M R_{\text {workpiece }}}$ \\
\hline
\end{tabular}

Material removed from the workpiece was estimated as a frustum of cone volume. In fact, the machined hole is not cylindrical due to the debris movement and secondary discharge occurring between the hole and the electrode side. Material removed from the tool was calculated as the volume of a hollow cylinder having Dext the external diameter of the electrode, Dint the internal diameter of the electrode and ht the measured tool wear.

\section{Analysis of the results}

Considering the large number of tested conditions, a Technology index was defined in order to resume the process parameters combination (peak current, voltage and frequency).

The Technology index was defined as:

Technology $=$ Peak Current $*$ Voltage $*$ Frequency 


\subsection{Tungsten carbide electrode}

Figure 1 and Figure 2 show machining time and MRR, calculated for each step, as a function of the achieved depth of the micro-holes and for different technologies. For sake of clarity, only some representative technological conditions are plotted. In general, as drilling progress, machining time of following sub-step slightly decreases; increasing the power discharge, the process time decreases strongly (comparing the maximum and the minimum power discharge curves, machining time for each step is halved). Some remarks can be drawn for MRR curves even though, in this case, the effect due to the increasing hole depth is more noticeable, partially because of the reduction of effective diameter along the hole depth (hole conicity).

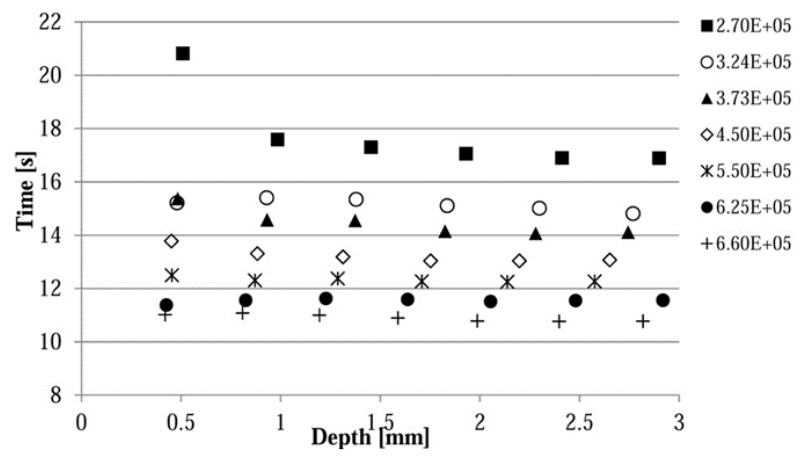

Fig. 1 Machining time calculated for each step, as a function of the achieved hole depth and for different technologies (tungsten carbide electrode)

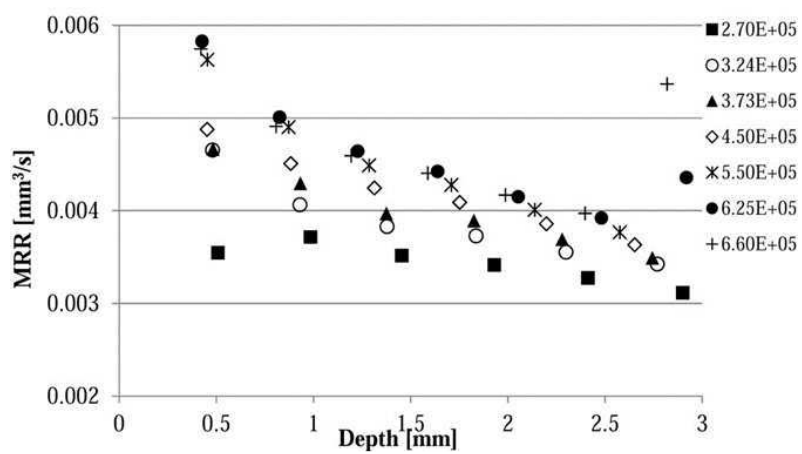

Fig. $2 M R R$ calculated for each step, as a function of the achieved hole depth and for different technologies (tungsten carbide electrode)

Tool wear as a function of the hole depth is reported in Figure 3. The wear, after an initial increasing with the depth, decreases slowly. High power discharge has a negative effect on the tool wear giving rise to a remarkable increase of this index. TWR curves (Figure 4) show always an increasing trend, despite the level of tool wear decreases. The increase of TWR for increasing hole depth is partially caused by the conical shape of the hole: in the last drilling steps the workpiece material removed is lesser since the permanence time of the tool is lower and then the parasite discharges are limited. Some of the present results are not fully in accord with other studies [12] since the use of high pressure internal flushing limits the debris accumulation at the bottom of the hole, that causes the abnormal discharges when a deep hole is executed.

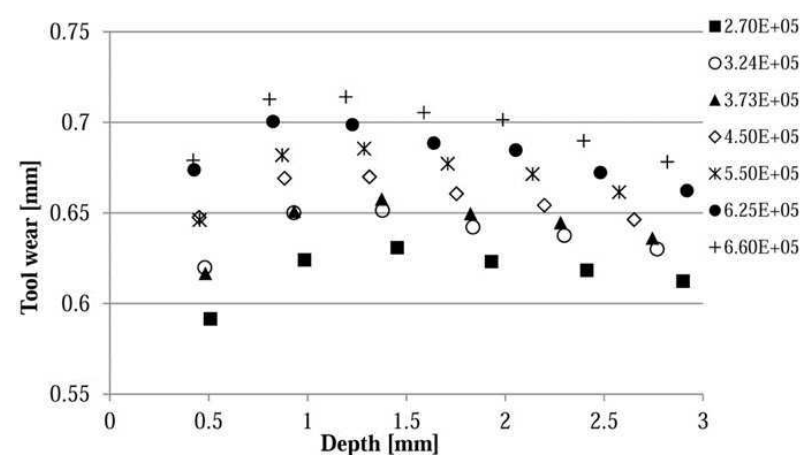

Fig. 3 Tool wear calculated for each step, as a function of the achieved hole depth and for different technologies (tungsten carbide electrode)

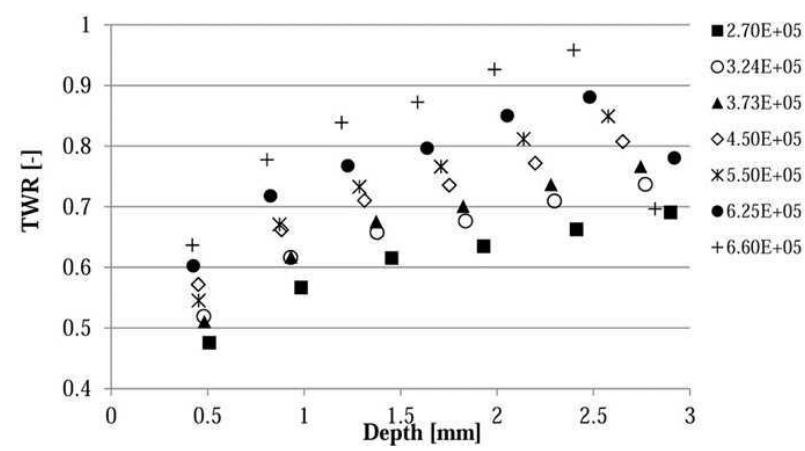

Fig. 4 TWR calculated for each step, as a function of the achieved hole depth and for different technologies (tungsten carbide electrode)

\subsection{Brass electrode}

Machining time for each step for brass electrode is reported in Figure 5; also in this case, only some representative number of technologies are shown.

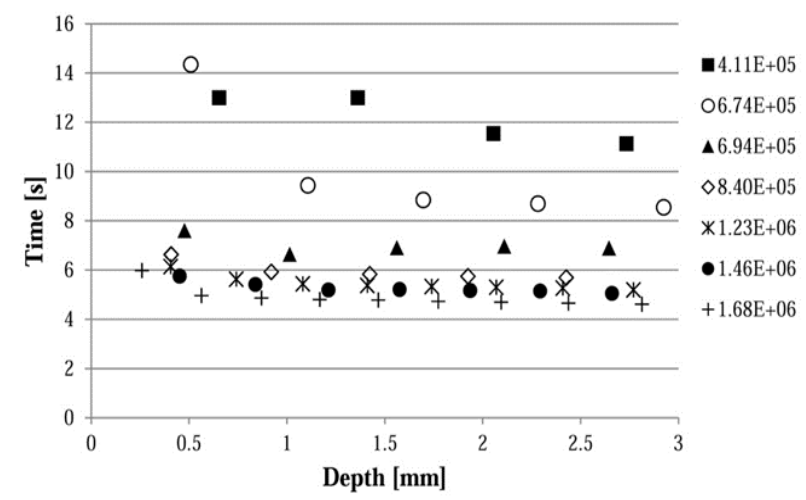

Fig. 5 Machining time calculated for each step, as a function of the achieved hole depth and for different technologies (brass electrode)

It can be observed that, when the drilling progresses, machining time of following sub-steps slightly decreases. Moreover, the effect of an increase of the power discharge is a decrease of the process time. The MRR for each step (Figure 6) decreases when the hole depth increases. Concerning the effect of power discharge, it can be observed that the maximum MRR curves correspond to intermedi- 
ate values of power discharge. This can be justified considering that in general the overcut increases when the machining time increases (and therefore reducing the power discharge). In this way, the effect of larger diameter may result in a greater MRR.

Tool wear and TWR for each step are shown in Figure 7 and Figure 8. Generally, the tool wear decreases when increasing the hole depth while, the tool wear is getting worse when the power discharge increases. TWR curves show a growing trend as a function of the hole depth, while the effect of the power discharge is the same as tool wear. The same consideration reported for the tungsten carbide electrode can explain this behavior.

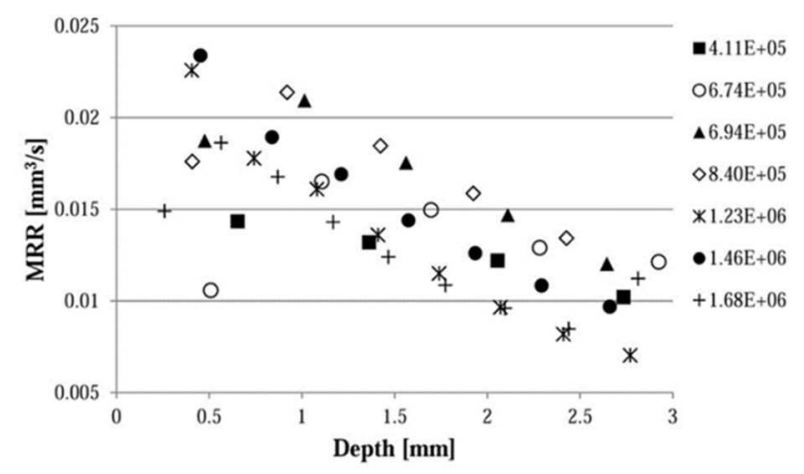

Fig. 6 MRR calculated for each step, as a function of the achieved hole depth and for different technologies (brass electrode)

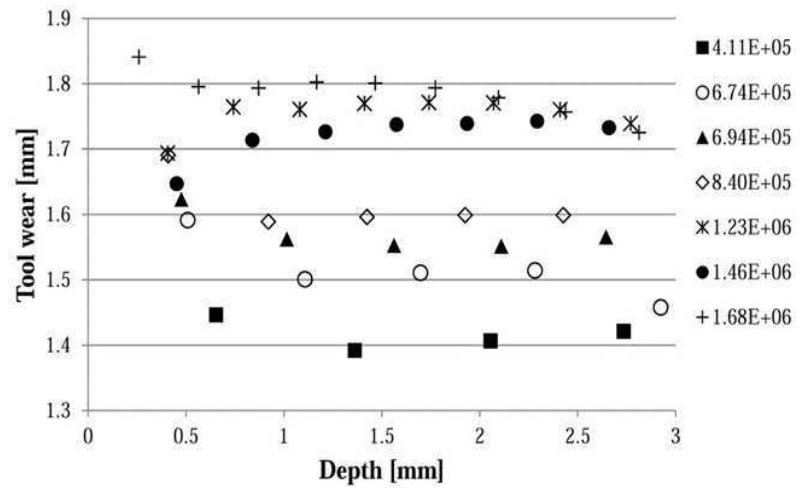

Fig. 7 Tool wear calculated for each step, as a function of the achieved hole depth and for different technologies (brass electrode)

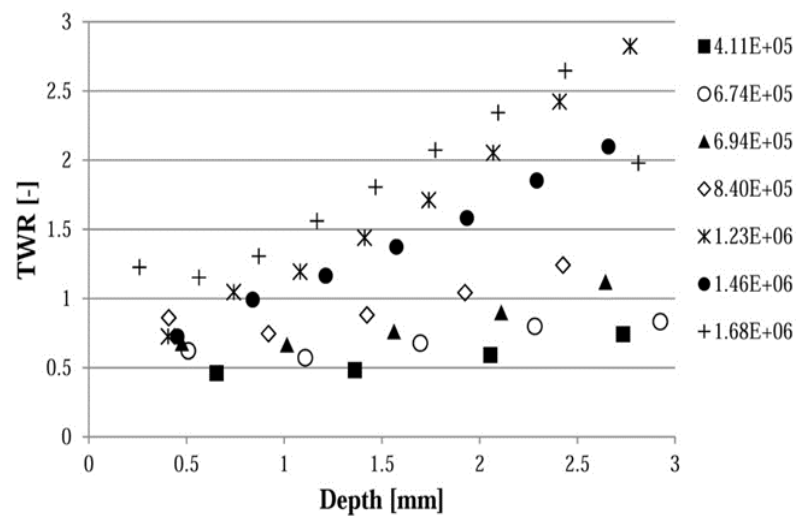

Fig. 8 TWR calculated for each step, as a function of the achieved hole depth and for different technologies

(brass electrode)

\section{Performance comparison between tungsten carbide and brass electrodes}

Figure 9 shows the comparison of the progressive MRR technology windows for tungsten carbide and brass electrodes. The progressive MRR is calculated as follows:

$$
M M R_{n}=\frac{\sum_{i=1}^{n} \text { MRworkpiece }_{i}}{\sum_{i=1}^{n} l_{i}}
$$

where MRworkpiece $i_{i}$ is the removed volume for the $i$-th step and $t_{i}$ is the machining time recorded at the $i$-th step. The limits of each region are defined by the process conditions giving rise to the minimum and maximum MRR. The behaviors of tungsten carbide and brass electrodes are interpolated by second degree polynomial curves ( $\mathrm{R}^{2}$ higher than 97\%). Since brass electrode has a higher electrical conductivity and commonly requires higher power discharge, it permits to obtain micro-holes more quickly. Moreover, while for the tungsten carbide electrode the difference between the maximum and the minimum curves is almost the same along the depth, for the brass electrode the advantage of using high power discharge is reduced as the hole depth increases.

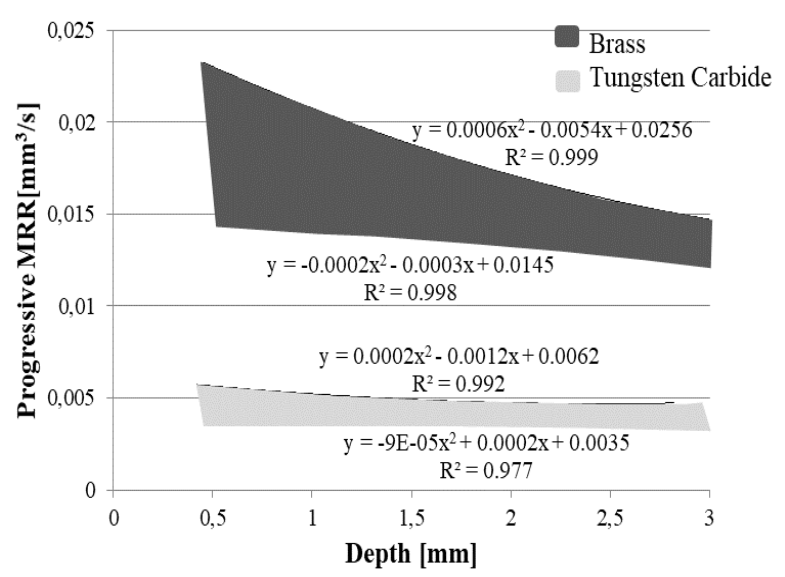

Fig. 9 Progressive MRR area for tungsten carbide and brass electrode

Figure 10 shows the comparison of progressive tool wear technology windows for tungsten carbide and brass electrodes. The trend of each condition is linear with a correlation index of $99 \%$. Tungsten carbide electrode, having a melting temperature higher than brass, is subjected to a minor wear; the wide technology window of brass electrode corroborates its sensitivity to the hole depth.

Figure 11 illustrates the progressive TWR area calculated as:

$$
\operatorname{TWR}_{n}=\frac{\sum_{i=1}^{n} \text { MRtool }_{i}}{\sum_{i=1}^{n} \text { MRworkpiece }_{i}}
$$

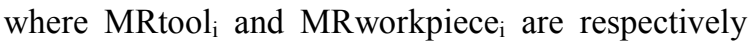
the electrode and the workpiece removed volume at the ith step. In this case the TWR of tungsten carbide and brass electrodes are interpolated by second degree polynomial curves. All the interpolating equations have a correlation 
index higher than $97 \%$. The overlapping of the TWR regions between brass and tungsten carbide demonstrates that brass electrode used with low power discharge permits to obtain values of TWR comparable to the tungsten carbide ones.

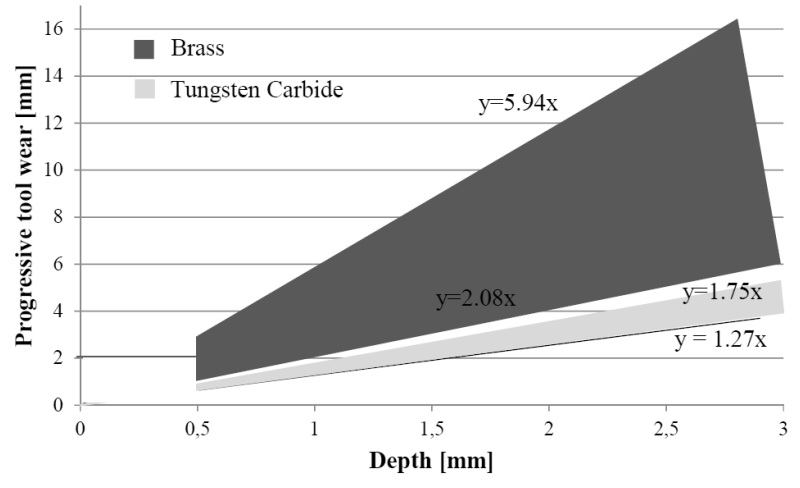

Fig. 10 Progressive tool wear area for tungsten carbide and brass electrodes

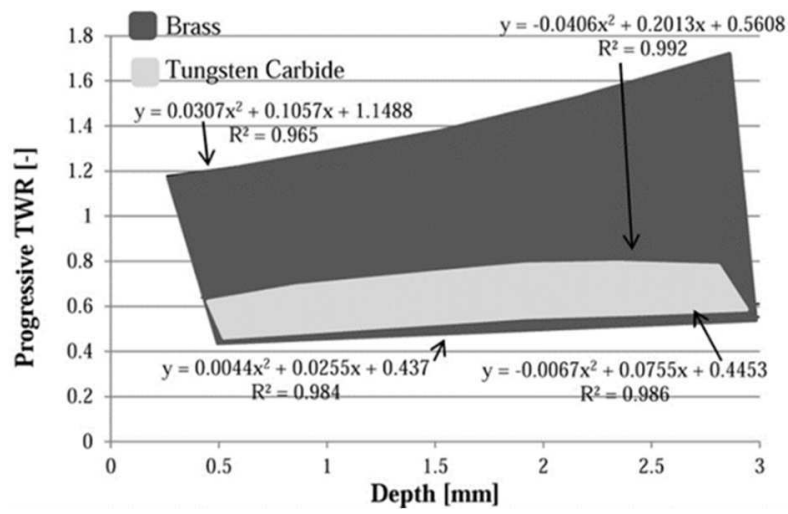

Fig. 11 Progressive TWR area for tungsten carbide and brass electrodes

\section{Conclusions}

The optimization of the process parameters for microEDM drilling contributes to improve the level of sustainability. For micro-EDM drilling process, the hole depth has a strong effect on the process performance. From this perspective, a study of the performance behavior during micro-EDM drilling on tungsten carbide, using two types of electrodes, was carried out; in particular, the evolution of the process performance during the entire drilling phase was analyzed.

In the range of the considered depth, as the process progressed, the performance has a generally linear trend. In general, with respect to the tungsten carbide electrodes, brass electrodes allow a higher MRR to the detriment of the tool wear. Anyway, in some experimental conditions, the level of wear of the two electrodes is comparable. In fact, TWR area diagram shows an overlapping of the regions of the two electrode materials.

The knowledge of the process performance is useful to predict MRR and TWR, as a function of the target hole depth, for both the tested electrodes. This prediction ability could be very useful in industrial applications during the entire decisional process where in most cases several constraints have to be satisfied.

\section{References}

[1] CHETAN, GHOSH, S., RAO, P.V. (2015). Application of sustainable techniques in metal cutting for enhanced machinability: a review. In: Journal of Cleaner Production, Vol. 100, pp. 17 - 34.

[2] SONA, S.M., LIMB, H.S., KUMARB, A.S., RAHMAN, M. (2007). Influences of pulsed power condition on the machining properties in micro EDM. In: Journal of Materials Processing Technology, Vol. 190, pp. $73-76$.

[3] MOURALOVA, K., BENES, L., ZAHRADNICEK, R. (2017). Defects in the surface layer of pure molybdenum after WEDM. In: Manufacturing Technology, Vol. 17, No. 5, pp. 786-790.

[4] VALAKI, J.B., RATHOD, P.P. (2016). Assessment of operational feasibility of waste vegetable oil based bio-dielectric fluid for sustainable electric discharge machining (EDM). In: Int $J A d v$ Manuf Technol, Vol. 87, pp. 1509 - 1518.

[5] SUNDARAM, M.M., PAVALARAJAN, G.B., RAJURKAN, K.P. (2008). A Study on Process Parameters of Ultrasonic Assisted Micro EDM Based on Taguchi Method. In: Journal of Materials Engineering and Performance, Vol. 17, pp. $210-215$.

[6] WEULE, H., et al. (2004). International state of the art of micro production technology. In: Production Engineering Research and Development, Vol. 11, No. 1, pp. $29-36$.

[7] MAHDAVINEJAD, R.A., MAHDAVINEJAD, A. (2005). ED machining of WC-Co. In: Journal of Materials Processing Technology, Vol. 162 163, pp. $637-643$.

[8] JAHAN, MP., RAHMAN, M., WONG, YS. (2011). A review on the conventional and microelectro discharge machining of tungsten carbide. In: International Journal of Machine Tools \& Manufacture, Vol. 51, pp. $837-858$.

[9] JAHAN, M.P., WONG, Y.S., RAHMAN, M. (2009). A study on the quality micro-hole machining of tungsten carbide by micro-EDM process using transistor and RC-type pulse generator. In: Journal of Materials Processing Technology, Vol. 209 , pp. $1706-1716$.

[10] LEE, S.H., LI, X. (2003). Study of the surface integrity of the machined workpiece in the EDM of tungsten carbide. In: Journal of Materials Processing Technology, Vol. 139, pp. 315 - 321.

[11] MOURALOVA, K., KOVAR, J., KARPISEK, Z., KOUSA, P. (2016). Optimization Machining of Titanium Alloy Ti-6Al-4V by WEDM with Emphasis on the Quality of the Machined Surface. In: Manufacturing Technology, Vol. 16, No. 6, pp. 1326-1331. 
[12] WANG, X., CHEN, L., DAN, B., WANG, F. (2018). Evaluation of EDM process for green manufacturing. In: Int J Adv Manuf Technol, Vol. 94, pp. $633-641$.

[13] D'UURSO, G., MACCARINI, G., MERLA, C., RAVASIO, C. (2011). The influence of electrode shape and material on micro EDM drilling process. In: Proceedings of the 9th International Conference on Multi-Material Micro Manufacture, Vienna, Austria, 2011.

[14] KUPPAN, P., RAJADURAI, A., NARAYANAN, S. (2008). Influence of EDM process parameters in deep hole drilling of Inconel 718. In: International Journal Advanced Manufacturing Technology, Vol. 38, pp. $74-84$.

[15] DENKENA, B., HOFFMEISTER, H.W., REICHSTEIN, M., ILLENSEER, S., HLAVAC, M. (2006). Micro-machining processes for microsystem technology. In: Microsystem Technology, Vol. 12, pp. $659-664$.

[16] LEE, S.H., LI, X. (2001). Study of the effect of machining parameters on the machining characteristics in electrical discharge machining of tungsten carbide. In: Journal of Materials Processing Technology, Vol. 115, pp. 344 - 358.

[17] JAHAN, M.P., WONG Y.S., RAHMAN, M. (2009). A study on the fine-finish die-sinking micro-EDM of tungsten carbide using different electrode materials. In: Journal of Materials Processing Technology, Vol. 209, pp. 3956 - 3967.

[18] YILMAZ, O.M., OKKA, A. (2010). Effect of single and multi-channel electrodes application on EDM fast hole drilling performance. In: International Journal Advanced Manufacturing Technology, Vol. 51, pp. $185-194$.

[19] PHAM, D.T., IVANOV, A., BIGOT, S., POPOV, K., DIMOV, S. (2007). An investigation of tube and rod electrode wear in micro EDM drilling. In: Int. J. Adv. Manuf. Technol, Vol. 33, pp. 103 - 109.

[20] D’URSO, G., LONGO, M., MACCARINI, G., RAVASIO, C. (2011). Electrical discharge machining of micro holes on titanium sheets. In: Proceedings of the 5th International Conference on Micro- and Nanosystems, ICONE14, Washington, DC, USA, 2011. 